\title{
Accounting
}

\section{Assessment of joint stock companies finance security risks in Ukraine}

\author{
Olena Stashchuk ${ }^{\mathrm{a}}$, Tetiana Shmatkovska ${ }^{\mathrm{b} *}$, Mykola Dziamulych ${ }^{\mathrm{c}}$, Anzhela Nikolaeva ${ }^{\mathrm{d}}$, Nataliia \\ Mostovenko ${ }^{\mathrm{d}}$, Myroslava Zabedyuk ${ }^{\mathrm{d}}$ and Lesia Ishchuk ${ }^{\mathrm{d}}$
}

\author{
${ }^{a}$ Department of Finance, Lesya Ukrainka Eastern European National University, Ukraine \\ ${ }^{b}$ Department of Accounting and Taxation, Lesya Ukrainka Eastern European National University, Ukraine \\ ${ }^{c}$ Department of Economics, Lutsk National Technical University, Ukraine \\ ${ }^{d}$ Department of Finance, Banking and Insurance, Lutsk National Technical University, Ukraine
}

\section{H R O N I C L E}

\section{Article history:}

Received: July 28, 2020

Received in revised format:

July 302020

Accepted: September 6, 2020

Available online:

September 11, 2020

Keywords:

Financial security

Financial risks

Indicators of financial security

Joint stock companies

\section{A B S T R A C T}

\begin{abstract}
Development of modern theoretical and methodological approaches and practical recommendations, which would take into account the specifics of the functioning of the financial system of Ukraine in general and its key elements under conditions of formation of a democratic society, macro-financial instability and geopolitical challenges, may ensure the financial security of joint-stock companies in the context of adapting them to the current realities of financial and economic activities. This paper analyzes the financial security risks of joint-stock companies by their individual components, which are manifested in the decrease or increase of the values of the respective indicators relative to the optimal ones, established by the questionnaire, and identified risk-forming factors. The emphasis is placed on the need to evaluate the extent of the impact of comprehensive restraining and stimulating financial risk to reflect the efficiency of formation and use of financial resources of joint-stock companies. Despite this, the need to determine the integrated financial risk, which shows the magnitude of the reduction of the desired level of financial security for a certain period, is justified. Developed and tested complex methodological approach for the analysis of financial risks of jointstock companies under the uncertain conditions and lack of statistical data for analysis, is a symbiosis of normative and fundamental approaches and substantiated by the synthesis of statistical, expert methods of scientific research and basic provisions of fuzzy logic theory. Using this approach allows us to identify and clearly visualize the scope of risk, to assess the extent of the impact of particular risk factors in a specific period and to determine the integral amount of risk, which allows to calculate the degree of reduction of financial security of joint-stock companies over a period of time.
\end{abstract}

\section{Introduction}

Modern financial science has accumulated a considerable amount of theoretical approaches, which are devoted for determining of the essence of financial security of economic entities and cover a wide range of concepts through the lens of financial security as an economic, social and philosophical phenomena. However, despite these accomplishments, there is a need to develop modern theoretical and methodological approaches and practical recommendations, which would take into account the specifics of the functioning of the financial system of Ukraine in general and its key elements under the conditions of formation of a

* Corresponding author.

E-mail address: shmatkovska2016@gmail.com (T. Shmatkovska) 
democratic society, macro-financial instability and geopolitical challenges, in order to ensure the financial security of jointstock companies in the context of adapting them to the current realities of financial and economic activity.

\section{Literature review}

Theoretical and methodological principles of interpretation of the concept of "financial security of economic entities", as well as the isolation of its factors and threats, laid down in the works of many scientists, in particular: Allen and Wood (2006), Geets (1998) and Lewis (2005). The analysis of the issues that determine the peculiarities of assessing the state of financial security of economic entities on the basis of various approaches are devoted researches (Donets, 2008; Epifanov et al., 2009; Kartuzov, 2012; Yakubiv et al., 2019; Copeland \& Murrin, 2000). Problems of research of the management mechanism of the financial security of enterprises have been reflected in the works of famous scientists (Azarenkova et al., 2016; Sodoma et al., 2018; Malik, 2017; Revak, 2009). The peculiarities of the functioning of joint-stock companies from the viewpoint of achieving them a secure state of financial activity are disclosed in the scientific works (Kyrylenko, 2005; Susidenko, 2018; Boiar et al., 2018; Tereshchenko \& Pavlovsky, 2018).

\section{Methodology}

The methodological basis of the work is a set of methods and principles that provide a value-based structure of scientific research, namely: methods of synthesis and analysis (to substantiate the conceptual characteristics of financial security of jointstock companies); Synectic method (for development of theoretical and methodological provisions on integral assessment of financial security of joint-stock companies); systematic analysis method and structural method (for improvement of methodology of assessing joint-stock companies financial security; developing a mechanism for managing financial security of joint-stock companies); indicator method (to evaluate typical indicators of financial security of joint-stock companies and establish their dynamics); integral method (for complex assessment of financial security level of joint stock companies); method of theoretical generalization (to determine the role and place of financial security in managing the performance of joint-stock companies); method of statistical and factor analysis (to systematize and evaluate the factors of influence on financial security in Ukraine; to assess the impact of financial factors on the state of financial security of joint-stock companies; to determine the relationship between the sources of capital formation of joint-stock companies and the level of their financial security); regulatory and fundamental method (to assess the extent of the impact of financial risks on the financial security of joint stock companies); method of grouping (to justify measures and mechanisms for ensuring financial security of joint-stock companies; systematization of threats and dominant features of financial security of joint-stock companies); graphical method (for visual presentation of the main research results); method of economic and mathematical modeling (to assess the efficiency of financial security management of joint stock companies); method of correlation analysis (to identify the most relevant financial factors affecting the financial security of joint-stock companies and the results of their financial and economic activities); expert method (for identification and systematization of threats and dominant factors of financial security of joint-stock companies; for identification of zones of influence of restraining and stimulating risk of financial security of joint-stock companies); a method of logical analysis and strategic management (to develop proposals on the use of threat-counteracting tools and multiply the dominant factors of financial security of joint-stock companies); extrapolation method (to assess the efficiency of financial security management of joint-stock companies from the investor's point of view). In financial science, risk assessment uses a number of methods, each with its own advantages and disadvantages, depending on the ultimate purpose of conducting a particular assessment. They can all be grouped into three groups:

1) methods for assessing the impact of certain factors (individual income, expenses) on the final result - profit, net income, the market value of a business entity, etc., and determine its level in a particular period;

2) methods by which short-term and medium-term forecasting of both factors and financial results are carried out on the basis of data for a certain previous period of time;

3) the methods by which a comprehensive risk assessment is performed, with the identification of their formalized and nonformalized types.

In addition, there is a broad list of peculiar classifications of risk assessment methods in the economic literature (Zorina, 2011). In order to substantiate our own approach to risk assessment, we consider it necessary to apply regulatory and fundamental methods of assessing them in symbiosis by determining the scope of the risks that led to an increase or decrease in the level of financial security, which is manifested in the corresponding change in its indicators, as well as integral financial risk, which will allow determining the degree of reduction of the general financial security of the joint-stock companies as a result of the effect of risk factors. At the same time, we take into account those indicators that most reflect the peculiarities of functioning of jointstock companies of mechanical engineering, and their deviation towards reduction from the optimum value will be considered as restraining financial risks (the sum of which forms an aggregate risk), which stipulate a threat to the joint-stock companies financial security, and those who, on the contrary, provided more than the optimum value of the indicator, will be considered as 
risks that have a stimulating effect on the financial and economic activity the business entities mentioned. The former point to financial security threats and the latter to dominants. Thus, we analyze the impact of risks on the financial security of joint-stock companies on the basis of a static analysis of the extent of the impact of risk-forming factors on the indicators of the financial condition of the studied entities. The technique for determining this effect in a specific time period is to calculate the ratio of the sum of the weights of indicators, which obtained negative values of absolute deviations of the indicators from the optimal, to the total sum of their weights. We consider it expedient to determine and reflect the impact of aggregate restraining financial risk on the overall level of financial security of joint-stock companies, the quantity of which is determined in the same way, but taking into account the cumulative value of negative deviations of indicators from optimum over a period of time and the total sum of these weights over the same period. In order to reflect the impact of financial risks on the state of financial and economic activity of joint-stock companies, it is supposed that they operate under conditions of stability and/or with the effective formation and use of capital and providing 100\% financial security. At the same time, this level of financial security will be considered desirable or ideal. As for the optimal values, they were expertly established using the basic techniques of the questionnaire. The surveyed employees include those who work in the planning and economic department and the financial reporting department (however, they are called differently in different joint-stock companies). They are directly related to analyzing and managing the financial security of joint-stock companies. In order to collect the necessary data, questions on the optimal values of the financial condition indicators of joint-stock companies of the machine-building complex of Ukraine were included in the content of the questionnaire with the proposal of short justification. The processing of these questionnaires generalized recommendations for establishing such optimal values of the coefficients-indicators of financial condition and their justification for the studied joint-stock companies (Table 1).

\section{Table 1}

Summary of the questionnaire on the establishment of optimal values of financial security indicators of joint-stock companies of mechanical engineering

\begin{tabular}{lcl}
\hline \multicolumn{1}{c}{ Indicator } & Optimal value & \\
\hline Wear coefficient of fixed assets & $<0.5$ & Exceeding this limit means that wear and tear reduction measures are required \\
\hline Return on assets & $>0$ increase & Mainly joint-stock companies in the industry receive losses, so reaching a break-even \\
Return on sales & $>0$ increase & $\begin{array}{l}\text { increase } \\
\text { point is a strategic goal }\end{array}$ \\
Return on equity & $>1$ & Indicates repayment of short-term liabilities on time \\
\hline Current ratio & $>0.5$ & Means the security of the interests of the owners \\
Autonomy Ratio (Solvency) & $<1$ & Indicates independence from creditors \\
Funding ratio & $>0.5$ & Provides speeding up the cycle of circulating capital \\
\hline Asset turnover ratio & $>1$ & The repayment of accounts receivable and accounts payable of enterprises quarterly is \\
Inventory turnover ratio & $>1$ & optimal \\
\hline Fixed assets turnover ratio & $>4$ & Exceeding this limit indicates the efficiency of financial and investment activities \\
\hline Accounts receivable turnover ratio & $>4$ & Indicates no loss \\
\hline Accounts payable turnover ratio & $>1$ &
\end{tabular}

The magnitude of the negative impact of a deterrent risk will be determined as follows:

$$
R_{s}=\frac{\sum i_{n-\Delta K}}{\sum i_{n}}
$$

where $\mathrm{R}_{\mathrm{s}}$ - the value of the deterrent financial risk;

$i_{n-\Delta K}$ - the sum of the weights of those coefficients, the absolute deviations of which are negative in a given period;

$i_{n}$ - the sum of the weights of all the coefficients in a particular year. Herewith, we will define the absolute deviations as follows:

$$
\Delta K_{n}=K_{f n}-K_{0 n}
$$

where $\Delta K_{n}$ - is the absolute value of deviations of safety status indicators from the optimum value in a particular year;

$K_{f n}$ - the actual value of the indicator in the same year;

$K_{0 n}$ - the optimal value of the indicator in a specific period.

The magnitude of the financial risk that has a positive impact on financial security will be determined as follows:

$$
R_{s t}=\frac{\sum i_{n+\Delta K}}{\sum i_{n}} \text { or } R_{s t}=S_{n}-R_{s}=1-R_{s}
$$

where $i_{n+\Delta K}$ - sum of the weights of positive absolute deviations of indicators from the optimum value in a specific period; $S_{n}$ - the ideal (desired) level of financial security in statics. The value of integral financial risk, which reduces the overall level 
of financial security over a certain period, will be determined as follows:

$$
R_{n}=\frac{\sum_{n=1}^{p} i_{n-\Delta K}}{\sum_{n=1}^{p} i_{n}}
$$

where $P$ - the number of years of a certain period of time. In addition, we consider it necessary to identify the source of risk by assessing the impact on the financial status indicators of the factors that shape them. That is, we will distinguish the risk-forming factors, which include those whose impact on the corresponding indicator will be greater. At the same time, the main task is to establish a measure of risk, which is determined by the impact of change in the relevant factor. In other words, determining the risk indicator (the value of which deviate in the direction of decrease from the optimal), it is necessary to conduct a factor analysis of the factors that influence it in order to highlight what caused the decrease of the corresponding coefficient. At the same time, another indicator should be considered as a financial risk stimulator, which determined the respective dominant of the financial security of joint-stock companies. Establishing relationships between factors and relevant indicators to determine the impact of the former on the outcoming indicator is advisable to make on the basis of the comparison of the growth rate. In order to simplify the said analysis, we introduce conventions for its formalization. Let the value of a certain financial security indicator be Z, the value of the numerator - X, the denominator - Y. Establishing relationships between factors and relevant indicators to determine the impact of the former on the outcoming indicator is advisable to make on the basis of the comparison of the growth rate. In order to simplify the said analysis, we introduce conventions for its formalization. Let the value of a certain financial security indicator be $Z$, the value of the numerator - X, the denominator - Y. Then the rate of increase in these variables will be TZ, TX, TY respectively. Considering that 14 coefficients (Table 1) have been assigned to the sample of analyzed financial security indicators of the joint-stock machine-building companies, each coefficient will be indicated on the specific order number of their placement in the given aggregate. For example, the wear factor is the first in the account, then its designations will look like Z1, X1, Y1, TZ1, TX1, TY1, etc. That is, the corresponding indicator in a certain year can be written as $Z_{i}, X_{i}, Y_{i}, T_{x_{i}}, T_{y_{i}}$ and as $Z_{i+1}, X_{i+1}, Y_{i+1}, T_{x_{i+1}}, T_{y_{i+1}}$ in each subsequent year. Therefore, the change in the growth rate of a certain indicator of the financial security of the joint-stock companies of the machine-building industry of Ukraine will depend on the changes in the growth rate of those quantities included in the formula of its calculation (Fig. 2):

$$
T_{Z_{i n}}=\frac{T_{x_{i n}}}{T_{y_{i n}}},
$$

where $T_{Z_{i n}}$ - is the rate of change of the i-th indicator of the financial security status of joint-stock companies of the n-th aggregate;

$T_{x_{i n}}$ - the rate of change of the numerator of the $\mathrm{i}$-th indicator of the $\mathrm{n}$-th aggregate;

$T_{y_{i n}}$ - the rate of change of the denominator of the $\mathrm{i}$-th indicator of the $\mathrm{n}$-th aggregate.

The above formula is obtained by mathematical substitutions by the following algorithm:

1) the formalization of the calculation of the factors;

2) instead of factors in the numerator and denominator written formulas of their calculating;

3) transformation of formulas in order to express the factors through the rate of their growth, by substitutions in the original formula with obtaining the result (Fig. 1).

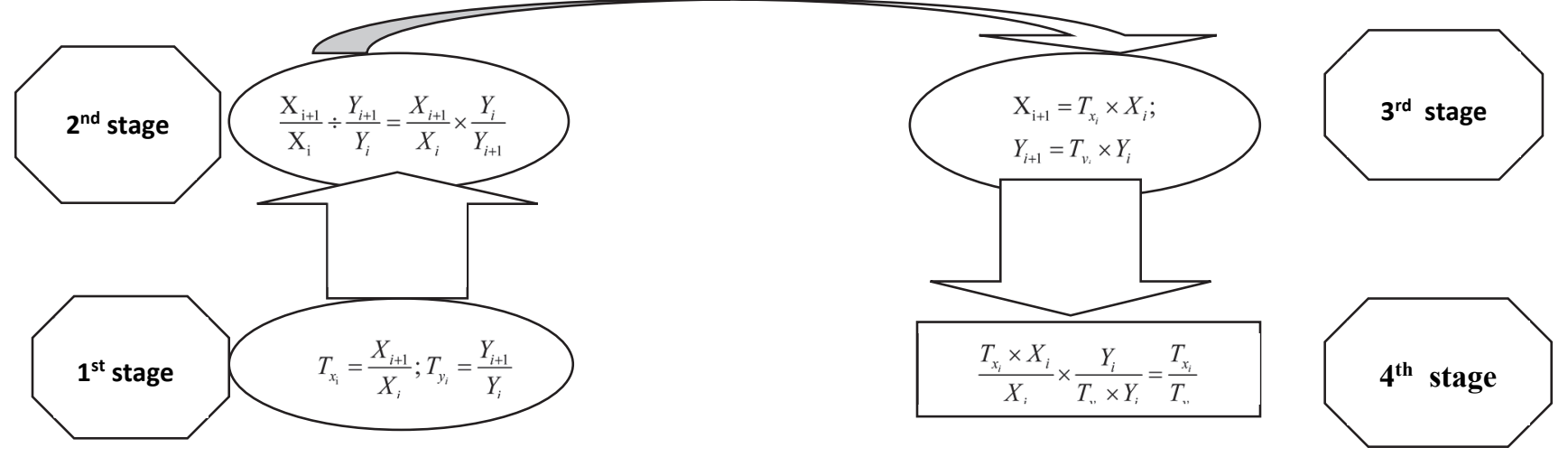

Fig. 1. Algorithm for deriving the formula of the correlation of factors and the resultant indicator of the state of financial security of joint-stock companies* 
In this case, the numerator is directly proportional to the resulting indicator, and the denominator is inversely proportional. However, the dynamics of the coefficient and its value (positive or negative) must be taken into account. In order to avoid distorted results, we will not calculate the rate of change of numerically opposite indicators (which is common in the financial statements of loss-making joint-stock companies). Instead, the influence of individual factors on the resulting indicator characterizing a particular risk zone of unprofitable joint-stock companies will be determined by the dynamics of absolute values of factor indicators.

\section{Results and discussions}

The activity of any business entity is influenced by various factors that can be classified as endogenous and exogenous. The former, of course, include those directly existing in the internal environment of business entity, the latter, those that are generated by the external. Both can be both stimulating and destructive, depending on the phase of the economic cycle of the state and the enterprise itself, socio-political or environmental conditions, etc. It is easy to measure this impact in a specific period of time, but it is very difficult in dynamics, since it is unknown when the transition from one stage of economic development to another will take place, or when the conditions that will partially or fundamentally change the landmarks of global cooperation, legal and social fields of the functioning of joint-stock companies or their own financial policies. It is the uncertainty that creates the risks and the basis for their generation in the market, causing positive and negative financial effects for the entity due to the influence of the relevant factors.

The negative impact of these factors appears in the risks that may weaken the financial security of the joint-stock companies, and the positive - in its strengthening. Static analysis of such an impact makes it possible to identify the weaknesses or strengths of financial and economic activity and, accordingly, to systematize the threats and/or dominant factors of the financial security of joint-stock companies in a certain period. However, in order to formulate a financial security strategy, it is necessary to forecast the development of joint-stock companies, taking into account internal and external factors, in order to develop an effective mechanism for identifying threats and risks and counteracting them, as well as enhancing the financial capacity of economic entities in order to increase their financial condition dominants, increase of the market value of the firm and formation of the investment image.

In other words, it is necessary to improve the mechanism of monitoring, analysis and counteraction of risks in the short and long term taking into account the uncertainty of the internal and external environment of the functioning of joint-stock companies, identification of the impact of endogenous and exogenous risk-forming factors in the direction of their quantitative and qualitative assessments by means of static and dynamic financial analysis. It should be noted that completely eliminating the effects of risks is impossible and not necessary, and the main task of both the strategy and tactics of risk management of jointstock companies, on the one hand, is to minimize their negative impact in order to counteract financial security threats, and on the other - to use risks for the multiplication of the financial security dominants of the surveyed business entities.

In the scientific literature, the concepts of "risk" and "threat" are generally not differentiated and used in parallel, even in terms of synonymous substitution of the essence of the same phenomenon, which has a negative impact on the financial security of an entity and which can be described as a danger. This is due to the fact that these concepts are similar in meaning. Partially agreeing with scientists, who emphasize that risk is the primary category of threat and derives from it (Kartuzov, 2012), as well as supporting the position of those who consider the concept of "threat" broader than the concept of "risk" (Bilousova et al., 2015), we believe that there is a causal link between them. Although the threat is the result of a risk due to the negative effects of certain endogenous or exogenous factors that disturb the financial equilibrium of the joint-stock companies, very often the risk is the cause of a new threat. Thus, in the analysis of the threat, you can point to the risk that caused it, or vice versa, to identify the risk that creates a particular threat. Therefore, the risk and threat categories are highly interrelated. Very often, in the process of identifying threats in the analysis of the financial security indicators of joint-stock companies, it is possible to identify the risks that cause the corresponding threats in the direction of systematization of factors affecting certain indicators of financial and economic activity, which led to the deterioration of the financial status of joint-stock companies at some stage of its functioning or capable of negatively affecting it in the future. However, the risks identified are axiomatic in nature and need to be quantified to confirm their validity. Instead, it is possible to define the scope of their activity, which is manifested by a decrease or increase in the level of financial security of joint-stock companies by individual component. At a time when the threat itself implies a deterioration of the financial security of a joint-stock company measured by certain indicators, the risk is always probabilistic and difficult to measure. At the same time, the threat itself is the basis for the risk or likelihood of the enterprise losing or not receiving the planned income, which is manifested in the decrease in the level of profitability of the joint-stock company and, ultimately, its bankruptcy. Therefore, the relationship between threat and risk can be summarized as follows (Fig. 2): 


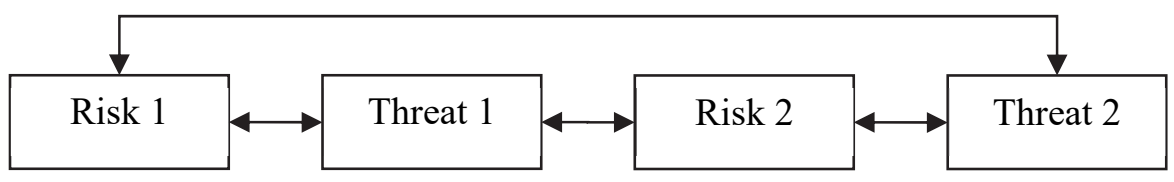

Fig. 2. Interaction of risk and threat categories*

*Source: compiled by the authors. It should be noted that understanding of risk as a probabilistic characteristic of financial results is extremely widespread in modern financial science. A number of scientific works are aimed at substantiation of approaches to risk assessment on the basis of classical statistical methods by calculating mathematical expectation, variance and standard deviation (Skakalsky, 2018). Having calculated the last 2 indicators, one can find the deviation of random values from their average expected values (Ivashchuk, 2008). However, if the deviation of a random variable from the mean is negative, then its mathematical expectation will be lower than the mean value, indicating the risk, and, conversely, if it is positive, the situation is favorable and the risk is minimal. Despite the widespread use of such a technique, we believe that it has a significant drawback that may distort the real state of affairs - the risk measure thus identified equally reflects the favorable and unfavorable deviations of the said random variable from the average. Therefore, it is not appropriate to use it in the conditions of limited statistical data and in comparing the risk level of functioning of profit and loss-making companies. From our point of view, risk itself is a metaphysical concept, and it can only be defined by verbally semantic coverage of content, and quantifying it is very difficult. Instead, it is important to measure its scope and impact on the financial security of joint-stock companies, resulting in the detection and systematization of either its threats or its dominants. That is, the risk can have not only a negative impact on the financial security of joint-stock companies, which is manifested in its threats, but also a positive one, the result of the influence of which is transformed into dominants. In assessing risk, we will understand it not by "risk" itself, but by "measure of risk" as a possible fluctuation of its impact on the financial security of joint-stock companies and try to identify and systematize the risk-forming factors, the impact of which is manifested in the corresponding risks.

We distinguish the areas of influence of financial risks that cause a negative and positive impact on the financial security of joint-stock companies as a result of deviation of the indicators from the optimum value in the direction of decrease and increase, and in order to increase the clarity of the obtained results, we show them in the table, separating the risk zones in darker colors (Table 2). Although the indicator itself cannot be a risk zone, the deviation of its value indicates the risks in a certain area of financial and economic activity which it characterizes.

\section{Table 2}

The scope of the restraining and stimulating financial risks of "Motor Sich" PJSC

\begin{tabular}{|c|c|c|c|c|}
\hline Indicator & 2015 & 2016 & 2017 & 2018 \\
\hline Depreciation of fixed assets & + & + & + & + \\
\hline Return on assets & + & + & + & + \\
\hline Return on sales & + & + & + & + \\
\hline Return on equity & + & + & + & + \\
\hline Current liquidity & + & + & + & + \\
\hline Solvency & + & + & + & + \\
\hline Financial dependence on borrowed funds & + & + & + & + \\
\hline Asset turnover & + & + & + & - \\
\hline Inventory turnover & - & - & - & - \\
\hline Fixed assets turnover & + & + & + & + \\
\hline Accounts receivable turnover & + & + & + & + \\
\hline Turnover of accounts payable & + & - & - & - \\
\hline Reinvestment & + & - & + & + \\
\hline Return on shares & + & + & + & + \\
\hline
\end{tabular}

Note. The risk areas are highlighted in dark colours

Source: compiled by the authors.

As can be seen from the Table 2, the weaknesses of financial and economic activity of PJSC "Motor Sich" are the risks of reducing business activity, in particular, the turnover of stocks during the entire study period and payables - in 2016-2018. The impact of these risks on the overall level of financial security of a joint-stock company can be represented using the diagram (Fig. 3). As can be seen from Fig. 3, the aggregate deterrent risk led to a decrease in the financial security level of the jointstock company by $4-14 \%$ in $2015-2018$, while $96-86 \%$ of this level was ensured by the effective management of the incentive risk. The average value of the integral restraining financial risk for the studied period in the amount of $10.5 \%$ indicates that the desired level of financial security is not reached by the corresponding value due to the negative influence of exogenous and endogenous factors. These include the dynamics of: net income from sales of products, a decrease of which in 2018 by $54.2 \%$ caused a decrease in asset turnover; the cost of sales, a decrease in the growth rate of which throughout the analyzed period led 
to a decrease in the inventory turnover indicator; values of current accounts payable, growth rates of which exceed the growth rates of net income from sales of products; retained earnings, which lagged behind the growth rate of net profit growth in 2016, caused underinvestment. In general, the integrated financial constraint for all studied joint-stock companies is shown in Fig. 4.

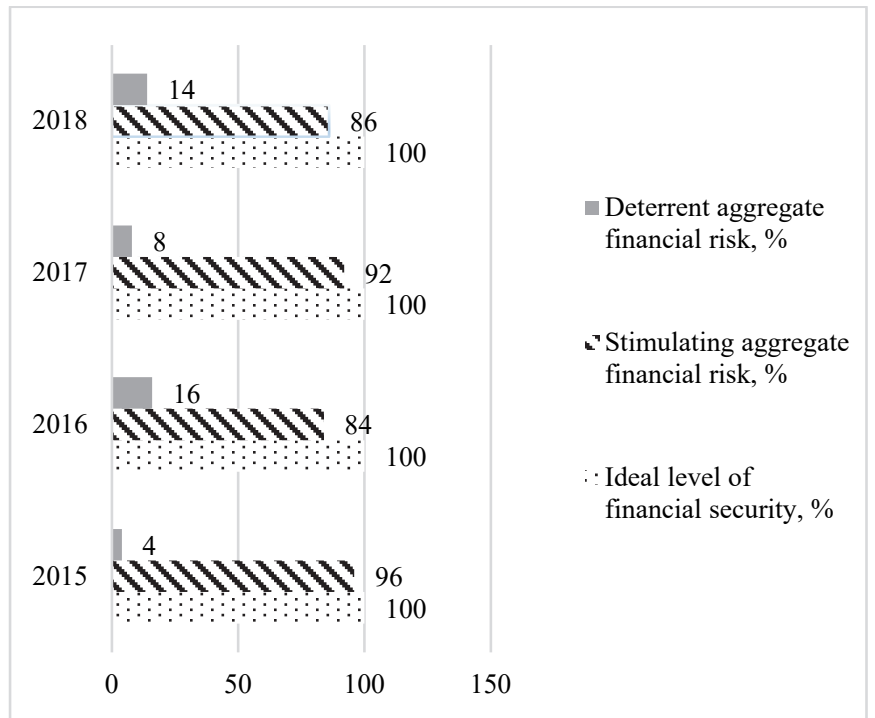

Fig. 3. Impact of restraining financial risk on the level of financial security of PJSC "Motor Sich" in 2015-2018, \%*

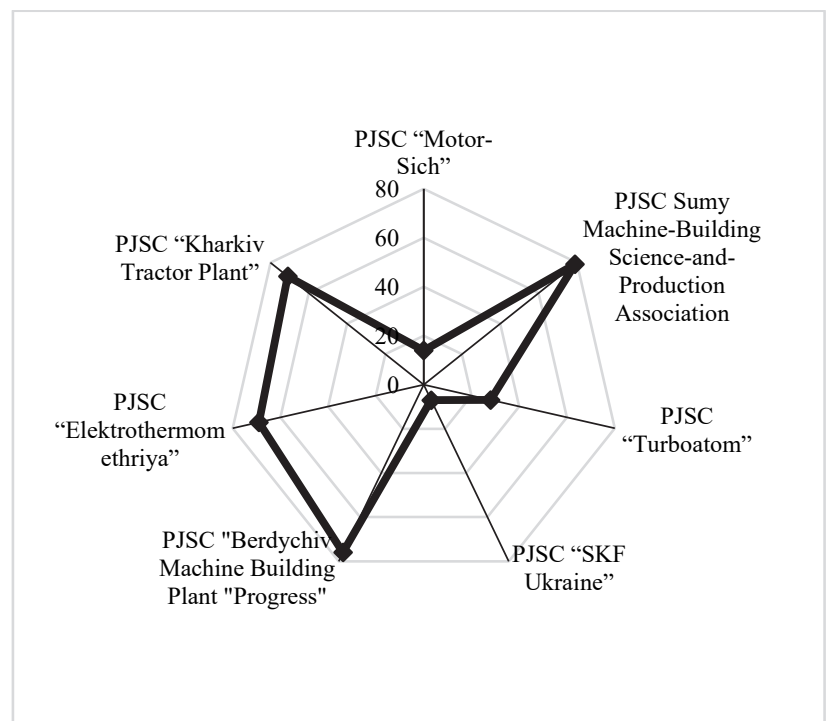

Fig. 4. Integral financial risk containment of joint-stock machinebuilding companies of Ukraine for the period 2015-2018*

*Source: compiled by the authors

Table 3

The scope of the restraining and stimulating financial risks of PJSC "SKF Ukraine"

\begin{tabular}{|c|c|c|c|c|}
\hline Indicator & 2015 & 2016 & 2017 & 2018 \\
\hline Depreciation of fixed assets & + & + & + & + \\
\hline Return on assets & + & + & + & + \\
\hline Return on sales & + & + & + & + \\
\hline Return on equity & + & + & + & + \\
\hline Current liquidity & + & + & + & + \\
\hline Solvency & + & + & + & + \\
\hline Financial dependence on borrowed funds & + & + & + & + \\
\hline Asset turnover & + & + & + & - \\
\hline Inventory turnover & + & + & + & + \\
\hline Fixed assets turnover & + & + & + & + \\
\hline Accounts receivable turnover & + & + & + & + \\
\hline Turnover of accounts payable & + & + & + & + \\
\hline Reinvestment & + & - & + & - \\
\hline Return on shares & + & + & + & + \\
\hline
\end{tabular}

Note. The risk areas are highlighted in dark colours

Source: compiled by the authors.

The impact of financial risks on the financial security of PJSC "SKF Ukraine", which determines its dominance and indicates its effective management, is almost absent. For example, restraining risks include only a decrease in the asset turnover ratio below the optimum value in 2018 and reinvestment in 2016 and 2018, which indicates the likelihood of a decrease in business and market activity (Table 3 ). This has influenced the integral restraining financial risk, which led to a decrease in the level of financial security from the desired by $5.5 \%$. The aggregate financial risk reduces the overall level of financial security by only $8 \%$ in 2016 and $14 \%$ in 2018 (Fig. 5), mainly due to a $25.7 \%$ decrease in net sales revenue in 2018 and a decrease in retained earnings by $45.3 \%$ and $176.4 \%$ in the corresponding years, as evidenced by the growth rates of the mentioned indicators. Unlike the previously analyzed joint-stock companies, the negative impact of deterrent financial risk on "Turboatom" PJSC is much larger and covers a wider range of its financial security components (Table 4, Fig. 6), and its integral value indicates a decrease in the overall financial security condition the analyzed period by as much as $25 \%$. The described situation is conditioned by the negative influence of the following risk-forming factors: significant deterioration of fixed assets, growth rates of which exceed the growth rates of their original value; the dynamics of net income from sales of products, a significant decrease in the growth rate of which compared to the growth rate of the comparable factors, led to a decrease in asset turnover in 2016 and 2018 , receivables turnover (2015-2016) and payables (2015-2018); change in the cost of sales, slow growth of which causes insufficient turnover of stocks to achieve the required level of financial security; growth in retained earnings, whose growth rate is far behind the growth rate of net income, which indicates a passive investment strategy of the joint-stock company and the 
lack of income from it. This conditioned the financial security of JSC "Turboatom" at the level below the ideal by $18 \%$ (Fig. 6). The excellent values of the absolute deviations of the other indicators attest to the effective management of the financial risks of the joint-stock company aimed at multiplying the financial security dominants, which provided $72-82 \%$ of the required level of financial security of this joint-stock company.

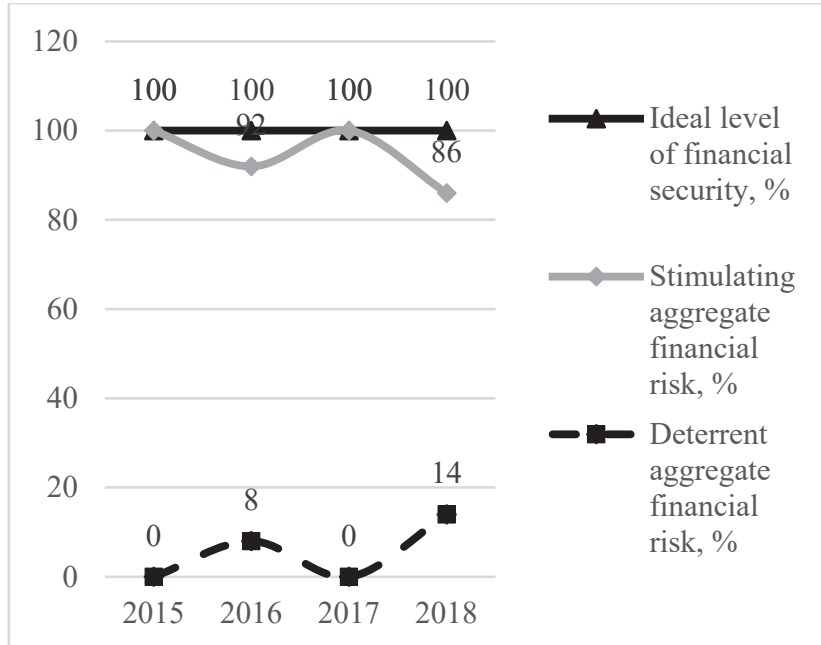

Fig. 5. Impact of restraining financial risk on the financial security level of PJSC "SKF Ukraine" in 2015-2018, \%*

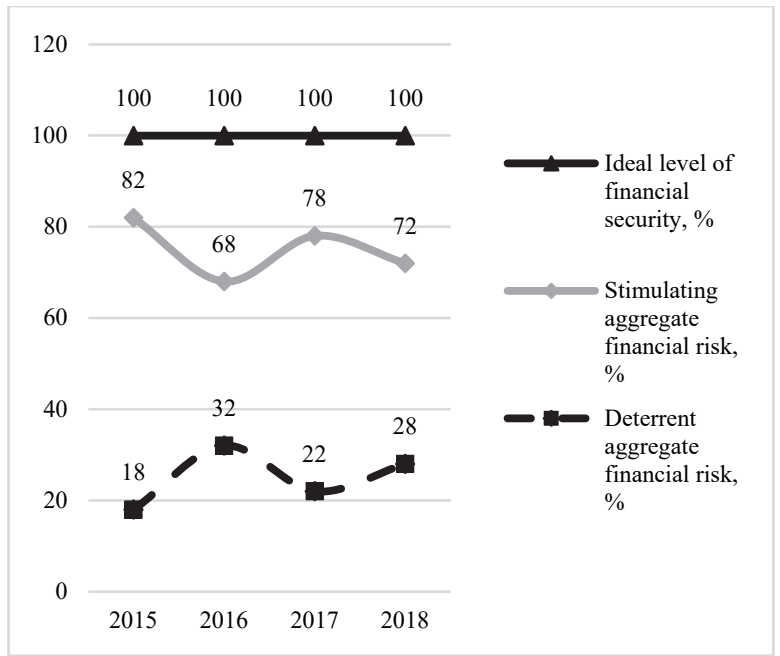

Fig. 6. Impact of restraining financial risk on the financial security level of PJSC "Turboatom" in 2015-2018, \%*

\section{Table 4}

The scope of the restraining and stimulating financial risks of PJSC "Turboatom"

\begin{tabular}{lcccc}
\hline \multicolumn{1}{c}{ Indicator } & $\mathbf{2 0 1 5}$ & $\mathbf{2 0 1 6}$ & $\mathbf{2 0 1 7}$ & $\mathbf{2 0 1 8}$ \\
\hline Depreciation of fixed assets & - & - & - & - \\
Return on assets & + & + & + & + \\
Return on sales & + & + & + & + \\
Return on equity & + & + & + & + \\
Current liquidity & + & + & + & + \\
Solvency & + & + & + & + \\
Financial dependence on borrowed funds & + & + & + & + \\
Asset turnover & + & - & + & - \\
Inventory turnover & - & - & - & - \\
Fixed assets turnover & + & + & + & + \\
Accounts receivable turnover & - & - & + & + \\
Turnover of accounts payable & - & - & - & - \\
Reinvestment & + & - & - & - \\
Return on shares & + & + & & + \\
\hline
\end{tabular}

Note. The risk areas are highlighted in dark colours

Source: compiled by the authors.

Instead, the negative value of the absolute deviations of the financial status indicators of LTD "Berdychiv Machine Building Plant "Progress" from the normative ones attests the negative impact of financial risks, which reduce the efficiency of financial and economic activity of this joint-stock company of the machine-building industry by virtually all constituents of financial security by $90 \%$ in $2015-2017$, up only $32 \%$ in 2018 . At the same time, the decrease in the level of financial security for the whole period is $75.5 \%$, as indicated by the integral value of the restraining financial risk. The multiplication of dominants in conditions of risk includes the effective management of assets and stocks throughout the period, as well as profitability, liquidity, fixed assets and reinvestment in 2018 (Table 5, Fig. 7). This was achieved through efficient inventory sales, which is reflected in the excess of the cost of sales (growth rate which directly affects the turnover of inventories) over the size of inventories almost 2 times during 2015-2018. Positive performance in 2018 is driven mainly by earning a net profit and increasing net sales revenue this year. The risk factors for the financial security of PJSC "Berdychiv Machine-Building Plant "Progress" include the following: depreciation of fixed assets, the growth rate of which exceeds the growth rate of their original value by almost 3 times; unprofitability of the joint-stock company, which caused the loss of its share capital, its activity as a whole and its separate components during 2015-2017 and the inability to reinvest funds in the development of the joint-stock company. 
Table 5

The scope of the restraining and stimulating financial risks of PJSC "Berdychiv Machine Building Plant "Progress"

\begin{tabular}{|c|c|c|c|c|}
\hline Indicator & 2015 & 2016 & 2017 & 2018 \\
\hline Depreciation of fixed assets & - & - & - & - \\
\hline Return on assets & - & - & - & + \\
\hline Return on sales & - & - & - & + \\
\hline Return on equity & - & - & - & + \\
\hline Current liquidity & - & - & - & + \\
\hline Solvency & - & - & - & - \\
\hline Financial dependence on borrowed funds & - & - & - & - \\
\hline Asset turnover & + & + & + & + \\
\hline Inventory turnover & + & + & + & + \\
\hline Fixed assets turnover & + & + & + & + \\
\hline Accounts receivable turnover & - & - & - & - \\
\hline Turnover of accounts payable & - & - & - & - \\
\hline Reinvestment & - & - & - & + \\
\hline Return on shares & - & - & - & + \\
\hline
\end{tabular}

Source: compiled by the authors.

Note. The risk areas are highlighted in dark colours

The risk factors also include the dynamics of current assets whose growth rates are lagging behind the growth rates of debt; change in equity, which decreased in 2016-2017; significant financial liabilities that significantly exceed the amount of equity; the dynamics of net income from the sale of products, the decrease of which caused low ratios of fixed assets, accounts receivable and payables, as evidenced by its growth rates and comparable factors; the change in the average annual value of assets, the growth rate of which decreases while reducing the growth rate of net sales income.

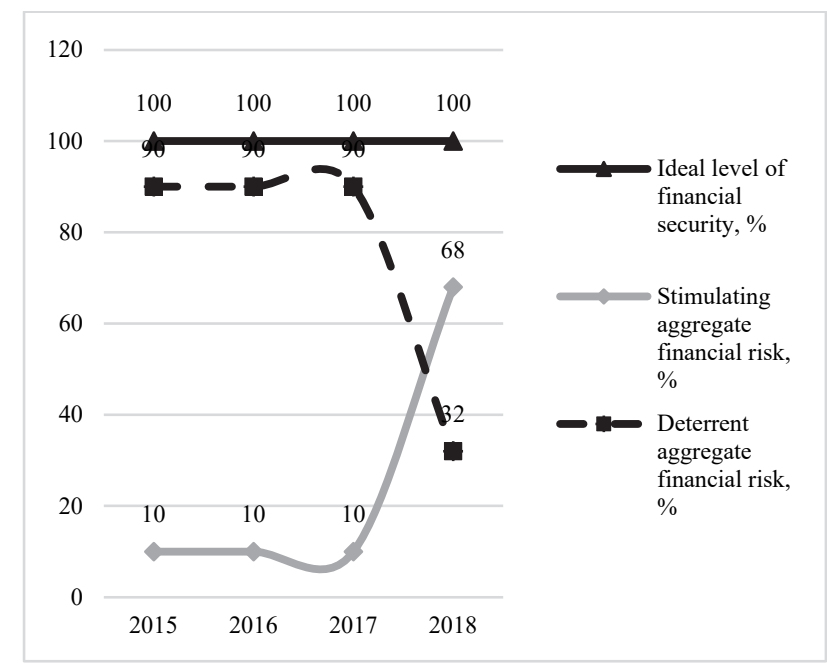

Fig. 7. Impact of restraining financial risk on the financial security level of PJSC "Berdychiv Machine Building Plant "Progress" in 2015-2018, \%*

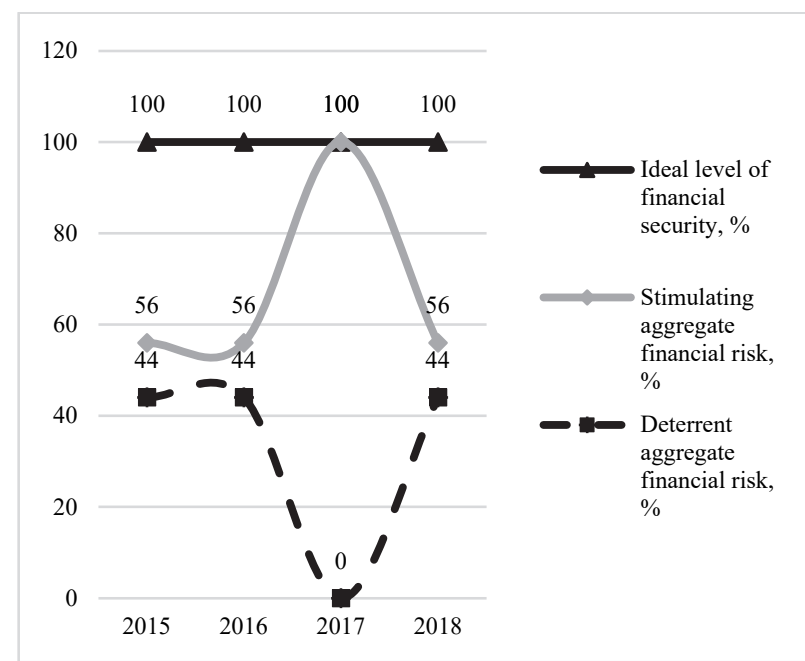

Fig. 8. Impact of restraining financial risk on the financial security level of PJSC "Elektrothermomethriya" in 2015$2018, \% *$

According to the estimation of absolute fluctuations of the financial condition indicators of PJSC "Elektrothermomethriya" it can be argued that management of its assets and equity under uncertainty is risky, which provides financial security $56 \%$ below the desired level by (Table 6, Fig. 8). Concerning the financial security risks of the Sumy Machine-Building Science-andProduction Association, they confirm the effectiveness of managing only fixed assets, other indicators of financial condition indicate a significant degree of restraining financial risks and reduce the level of financial security by $66-78 \%$ in $2015-2018$ and $76.5 \%$ over the whole period (Table 7, Fig. 9). According to the assessment of the growth rate of the financial security indicators of the joint-stock company and the factors that determine them, the following are included in the risk-forming factors: absolute loss, which leads to the unprofitability of the joint-stock company; the dynamics of current assets, which slows down the growth rate which causes a decrease in liquidity; the negative value of equity, which determines the negative value of the autonomy and financing ratios; change in net income from sales of products, the decline of which leads to a decrease in the indicators of asset turnover, accounts receivable and payables. A similar situation is observed at PJSC "Kharkiv Tractor Plant", risk-forming factors of financial security which are identical to the ones just mentioned (Table 8, Fig. 10). It is worth noting that some aspects of managing its financial security indicate higher efficiency than PJSC Sumy Machine-Building Science-and-Production Association. 


\section{Table 6}

The scope of the restraining and stimulating financial risks of PJSC "Elektrothermomethriya"

\begin{tabular}{|c|c|c|c|c|}
\hline Indicator & 2015 & 2016 & 2017 & 2018 \\
\hline Depreciation of fixed assets & + & + & + & + \\
\hline Return on assets & - & - & + & - \\
\hline Return on sales & - & - & + & - \\
\hline Return on equity & - & - & + & - \\
\hline Current liquidity & + & + & + & + \\
\hline Solvency & + & + & + & + \\
\hline Financial dependence on borrowed funds & + & + & + & + \\
\hline Asset turnover & + & + & + & + \\
\hline Inventory turnover & + & + & + & + \\
\hline Fixed assets turnover & + & + & + & + \\
\hline Accounts receivable turnover & + & + & + & + \\
\hline Turnover of accounts payable & + & + & + & + \\
\hline Reinvestment & - & - & + & - \\
\hline Return on shares & - & - & + & - \\
\hline
\end{tabular}

Note. The risk areas are highlighted in dark colours

Source: compiled by the authors.

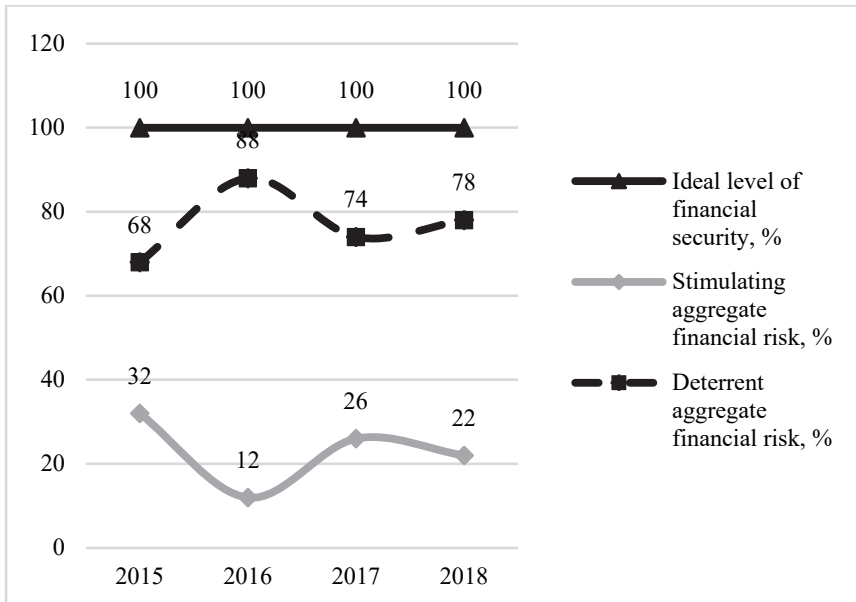

Fig. 9. Impact of restraining financial risk on the financial security level of PJSC Sumy Machine-Building Science-andProduction Association in 2015-2018, \%*

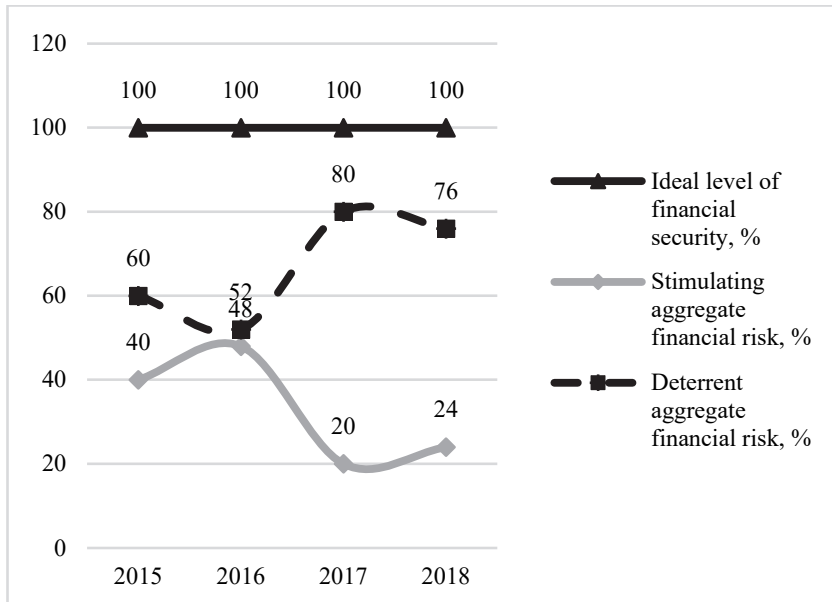

Fig. 10. Impact of restraining financial risk on the level of financial security of PJSC "Kharkiv Tractor Plant" in 2015$2018, \% *$

*Source: compiled by the authors

\section{Table 7}

The scope of the restraining and stimulating financial risks of PJSC Sumy Machine-Building Science-and-Production Association

\begin{tabular}{|c|c|c|c|c|}
\hline Indicator & 2015 & 2016 & 2017 & 2018 \\
\hline Depreciation of fixed assets & + & + & + & + \\
\hline Return on assets & - & - & - & - \\
\hline Return on sales & - & - & - & - \\
\hline Return on equity & - & - & + & + \\
\hline Current liquidity & + & - & - & - \\
\hline Solvency & - & - & - & - \\
\hline Financial dependence on borrowed funds & - & - & - & - \\
\hline Asset turnover & + & - & - & - \\
\hline Inventory turnover & + & - & + & - \\
\hline Fixed assets turnover & + & + & + & + \\
\hline Accounts receivable turnover & - & - & - & - \\
\hline Turnover of accounts payable & + & - & - & - \\
\hline Reinvestment & - & - & - & - \\
\hline Return on shares & - & - & - & - \\
\hline
\end{tabular}

This applies, in particular, to the value of the integral restraining financial risk, which is less by $6 \%$ compared to the value in PJSC Sumy Machine-Building Science-and-Production Association. This is due to the effective management of inventories in 2015-2018 and assets in 2015-2017. 
The scope of the restraining and stimulating financial risks of PJSC "Kharkiv Tractor Plant"

\begin{tabular}{|c|c|c|c|c|}
\hline Indicator & 2015 & 2016 & 2017 & 2018 \\
\hline Depreciation of fixed assets & + & + & + & + \\
\hline Return on assets & - & + & - & - \\
\hline Return on sales & - & + & - & - \\
\hline Return on equity & + & - & - & + \\
\hline Current liquidity & - & - & - & - \\
\hline Solvency & - & - & - & - \\
\hline Financial dependence on borrowed funds & - & - & - & - \\
\hline Asset turnover & + & + & + & - \\
\hline Inventory turnover & + & + & + & + \\
\hline Fixed assets turnover & + & + & - & - \\
\hline Accounts receivable turnover & + & - & + & + \\
\hline Turnover of accounts payable & + & - & - & - \\
\hline Reinvestment & - & - & - & - \\
\hline Return on shares & - & + & - & - \\
\hline
\end{tabular}

Note. The risk areas are highlighted in dark colours

Source: compiled by the authors.

\section{Conclusions}

Thus, the financial security of joint-stock companies of the machine-building complex is influenced by risk-generating and stimulating factors, the totality of which determines the degree of influence of financial risks on the efficiency of formation and use of financial resources of the mentioned economic entities, reducing or, conversely, increasing it. The paper has analyzed the financial security risks of joint-stock companies by their individual components manifested in the decrease or increase in terms of the values of the respective indicators relative to the optimal ones, established by the questionnaire, and identified riskforming factors. Emphasis is placed on the need to evaluate the extent of the impact of comprehensive restraining and stimulating financial risk to reflect the efficiency of formation and use of financial resources of joint-stock companies. Despite this, the need to determine the integrated financial risk, which shows the magnitude of the reduction of the desired level of financial security for a certain period, was justified. Developed and tested complex methodological approach to the analysis of financial risks of joint-stock companies in the conditions of uncertainty and lack of statistical data for analysis, is a symbiosis of normative and fundamental approaches and substantiated by the synthesis of statistical, expert methods of scientific research and basic provisions of fuzzy logic theory. Using this approach allows us to identify and clearly visualize the scope of risk, to assess the extent of the impact of particular risk factors in a specific period and to determine the integral amount of risk, which allows to calculate the degree of reduction of financial security of joint-stock companies over a period of time. The implementation of this approach will facilitate the early identification of areas of restraining and stimulating financial risks and the factors that caused them, and accordingly rapid development of measures to counteract threats or increase the dominants, depending on the deterioration/improvement of the financial status of the joint-stock company to achieve its desired level.

\section{References}

Allen, W., \& Wood, G. (2006). Defining and achieving financial stability. Journal of Financial Stability, 2(2), $52-57$.

Azarenkova, G. M., Bondarenko, I. Yu., \& Azarenkov, S. G. (2016). Ensuring the financial security of the enterprise as the basis of its effective activities. Financial and Credit Activities: Problems of Theory and Practice, 1, $168-176$.

Bilousova, O. S., Garkavenko, V. I., \& Danylenko, A. I. (2015). Risks and threats to financial security of the public finance sector and ways to overcome them. Academy Financial Management. Kyiv.

Boiar, A. O., Shmatkovska, T. O., \& Stashchuk, O. V. (2018). Towards the theory of supranational finance. Cogent Business \& Management, 5(1). DOI: 10.1080/23311975.2018.1482594.

Copeland, T., Koller, T., \& Murrin, D. (2000). Valuation: Measuring and Managing the Value of Companies. 3-rd edition. New York.

Donets, L I., \& Vashchenko, N. V. (2008). Economic security of the enterprise. Center for Education. Kyiv.

Epifanov, A. A., \& Plastun, O. L. (2009). Financial security of enterprises and banking institutions. Academy of Banking. Sumy.

Geets V. M. (1998). The concept of economic security of Ukraine. Economist, 7(9), 63-82.

Ivashchuk, O. T. (2008). Economic and mathematical modeling. TNEU. Ternopil.

Kartuzov, E. P. (2012). Influence of risks and threats on the state of financial security of enterprises. Actual Problems of Economy, 9(135), 115-124.

Kyrylenko, V. I. (2005). Investment component of economic security. KNEU. Kyiv.

Lewis, D. S. (2005). Financial security \& personal wealth. Transaction Publishers. Ney York.

Malik, O. V. (2017). The mechanism of financial security management of the enterprise. Economic Space: A Collection of Scientific Works of the Dnipro State Academy of Civil Engineering and Architecture, 99, 154-166. 
Revak, I. O. (2009). The mechanism of financial security of Ukraine: theoretical aspect. Scientific Bulletin of Lviv State University of Internal Affairs. Economic Series, 2, 238-247.

Skakalsky, Y. S. (2018). Controlling of financial risks of the enterprises: dis. Ph. D. (econ. Science). Kyiv.

Sodoma, R., Skhidnytska, H., Shvorak, A., Shmatkovska, T., Zhurakovska, I. (2018). Peculiarities of agrarian receipts as a modern financial tool. Economic annals - XXI, 169(1-2), 46-49. DOI: 10.21003/ea.V169-09.

Statistical information. State Statistics Service of Ukraine. (2020) http://www.ukrstat.gov.ua/operativ/oper_new.html.

Susidenko, O. V. (2018). Financial security of the enterprise: theory, methods, practice. Center for Education. Kyiv.

Tereshchenko, O. O., Pavlovsky, S. V. (2018). Improving the financial mechanism of crisis management of the enterprise. Finance of Ukraine, 6, 108-123.

Yakubiv, V., Sodoma, R., Hrytsyna, O., Pavlikha, N., Shmatkovska, T., Tsymbaliuk, I., Marcus, O., Brodska, I. (2019). Development of electronic banking: a case study of Ukraine. Entrepreneurship and Sustainability Issues, 7(1), $219-232$. DOI: $10.9770 /$ jesi.2019.7.1(17).

Zorina, O. A. (2011). Methods of financial risk analysis. International Collection of Scientific Works, 2(20), $221-229$.

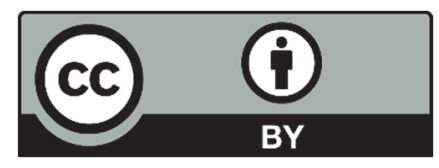

(C) 2020 by the authors; licensee Growing Science, Canada. This is an open access article distributed under the terms and conditions of the Creative Commons Attribution (CC-BY) license (http://creativecommons.org/licenses/by/4.0/). 